\title{
Services and Seasonal Demand
}

\author{
Steven M. Shugan ${ }^{1}$ \\ and
}

\section{Sonja Radas ${ }^{2}$}

\begin{abstract}
${ }^{1}$ Steven M. Shugan is the Russell Berrie Eminent Scholar Chair and Professor of Marketing at the Warrington College of Business at the University of Florida, 218 Bryan Hall, Gainesville, FL 32611-2017, Phone: 352-392-1426 x1236, Fax: 846-0457.

${ }^{2}$ Sonja Radas is an Assistant Professor of Marketing at the Olin School of Business at Washington University.
\end{abstract}

The authors thank the Russell Berrie Foundation for helping finance the data collection in this article. Both authors contributed equally to this article. 


\begin{abstract}
Seasonality impacts nearly every product and service. The impact of seasonality on service providers is especially important because these providers are often unable to adapt to seasonal changes in demand through traditional methods such as inventory control and switching manufacturing lines to counter-cyclic products. In this chapter, we discuss (1) the contemporary methodologies for modeling seasonality, (2) the implications of those models of seasonality on new product introductions, and (3) the implications of those models of seasonality on techniques for managing seasonal demand such as demand shifting.
\end{abstract}




\section{INTRODUCTION}

Seasonality is so prevalent that nearly every service in every country experiences its effect. Although seasonal items such as toys and Christmas trees immediately come to mind, seasonality influences marketing strategies in nearly every industry. For example, annual government actions, such as taxation, have a dramatic effect on accounting services, brokerage services, banking and, even, book retailing. Annual sports seasons have a dramatic impact on the marketing strategies of advertisers, the promotional programs of retailers and the scheduling of competitive entertainment services. The school year impacts travel-related services such as airlines, hotels, car rentals, as well as, retailing and entertainment services.

In many cases, one industry's seasonality causes another industry's seasonality. Christmas, for example, creates seasonal sales for retailers. Sales in retailing, in turn, creates seasonality for services who sell to retailers such as transportation services, credit-checking services, display assembly services and delivery services. The same effect occurs in other industries where, for example, sporting events impact hotels and restaurants while new auto releases in the autumn may create demand in auto-related industries as well as companies supplying credit for car-buyers.

Manufactured goods often mitigate the impact of seasonality with the use of different inventorying strategies. These inventory strategies help smooth production and labor problems associated with off-peak demand. Service providers, unfortunately, are often not as lucky. Their ability to inventory services is far more limited. That inability leads to both marketing and operational problems associated with seasonal demand (e.g., see Lovelock 1984). In this chapter, we focus on the implications of seasonality for marketing decisions. We start by more carefully defining seasonality.

\section{SEASONALITY DEFINED}

Seasonality involves predictable and uncontrollable variations in demand over time. The predictability usually follows from a recurrent pattern associated with events or activities. The precise pattern and the relevant time interval, however, can vary dramatically from industry to industry. Seasonal patterns can be associated with, for example, peak demand that lasts for hours, days, weeks, months, years or some combination of time periods. These demand peaks can recur following almost any predictable and uncontrollable pattern.

Health clubs, for example, experience hourly seasonal patterns of demand, peaking in the evening and early morning when many members are not working. Motion picture 
exhibitors can experience daily seasonal patterns in demand, finding that most moviegoers visit on weekends. Airlines experience monthly seasonality with demand-peaking during the summer season. The Olympic games cause shifts in demand in sports related industries every four years. Still another example is restaurants who experience multiple seasonal patterns in demand. The restaurant industry, for example, experiences hourly seasonal patterns reflecting times of meals: breakfast, lunch and dinner. The restaurant industry experiences daily seasonal demand with demand peaking on weekends. The industry also experiences annual seasonal patterns associated with holidays such as Mothers Day and Thanksgiving.

We now discuss these different aspects of seasonality in turn.

\section{ASPECTS OF SEASONALITY}

\section{Predictable Demand Variations}

We have defined seasonality as being predictable. In most cases, this predictability is associated with recurring events which are beyond the control of any one firm. We must distinguish these uncontrollable events from usual unpredictable variations in demand. Unpredictable variations in demand often result from random chance and, by definition, fail to exhibit well-defined cycles. These unpredictable variations in demand may occur when a large number of customers suddenly and simultaneously demand, by chance, the use of a particular service. For example, a large number of customers may suddenly arrive, by chance, at a supermarket or at a bank. Several construction projects may, by chance, begin on the same date, and each project may demand the same services from architects, carpenters, masons, concrete contractors and so on.

The management of unpredictable demand is fundamentally different than the management of predictable demand variations. A service provider, for example, anticipating a high season may raise prices during the high season to benefit from the increase in demand. With unpredictable variations in demand, a service provider may be unable to find a profitable way to exploit a sudden increase in demand or stimulate demand when few customers arrive. For example, restaurants usually are unable to raise or lower prices instantly when an evening brings unexpectedly high or low demand, respectively.

Moreover, unlike seasonality, unpredictable variations in demand usually are unique

to an individual service provider and not common across all service providers. Hence, the management of unpredictable demand is fundamentally different because customers are immediately lost to competitors. A restaurant, for example, that experiences a sudden, unexpected increase in demand may lose customers to a competitive restaurant 
who is not experiencing a similar increase in demand. During common peak periods, however, such as weekend evenings, both restaurants are operating at capacity. When at capacity, neither loses demand to the other. This argument suggests that the nature of competition is different when demand variations are predictable. Moreover, the nature of competition may also be different when a service industry is operating at capacity.

\section{Uncontrollable Demand Variations}

The second aspect of seasonality is the inability to control seasonal variations in demand. Unlike demand shifts made possible through promotional activities or advertising, seasonal demand changes are beyond the control of any one firm. For example, numerous industries, such as movie exhibitors, amusement parks and children's camps, experience demand related to the children's school year. For all practical purposes, each service provider must treat seasonal demand as exogenous and beyond their immediate control.

With seasonality, each service provider still retains the ability to influence their own demand using marketing tools such as advertising and pricing. Seasonality, however, will have an uncontrollable impact on the responsiveness of most marketing tools. The same price reduction or promotional effort, for example, may generate more demand during a high season than during a low season.

Note that, we should distinguish between the impact of seasonality on demand and its impact on sales. We usually observe only the sales of an industry and not its demand. In most cases, observing industry sales patterns may be sufficient for measuring seasonal patterns. For example, the box office sales of all motion pictures should reflect the seasonal demand for motion pictures. However, by observing sales, we are only observing the demand curve at a single point. To make very accurate comparisons across time, we must assume that marketing practices are roughly constant. But when the seasonal pattern influences the industry's marketing practices, the sales curve may not perfectly reflect the underlying pattern. Were firms, for example, to increase their prices during peak-seasons, industry sales during peak seasons might underestimate the true seasonal pattern because the increased prices might decrease industry peak sales and produce the appearance of less variation in demand across seasons. The same problem would occur when the industry operates at capacity during the peak season and demand exceeds capacity. Here again, the observed sales may underestimate the impact of seasonality on demand. Hence, observed sales may provide only an approximation for observed seasonal patterns. It might be more accurate to also examine obvious endogenous factors, such as changes in price, to refine the seasonal pattern observed in industry sales. Never-the-less, given the little research done on seasonality, it might be best to use that approximation than to ignore the influence of seasonality. 


\section{CAUSES OF SEASONALITY}

\section{Natural Causes}

The historic cause for seasonality has been the transition between the four divisions of the year: Summer, Fall, Winter and Spring. These seasons were predictable as each begins at an equinox or solstice. The seasons brought specific climatic changes and dramatic effects on industries such as agriculture. Given that many early economies were primarily agricultural, and some continue to be so today, seasonality played and continues to play an important role in many economies.

Seasonality also played an important role in history. Many festivals and holidays revolve around annual seasons. Political and military campaigns were planned around seasons. Many religious events and religious undertakings were also planned around annual seasons.

As seasons approach, some products or services may become unavailable or available only at lower quality levels. For example, fruits and vegetables may become unavailable and the quality of certain fish, Lobster and other seafood may vary from season to season. Moreover, the types of customers may change. A hotel in Orlando Florida may be, for example, the destination for families with children during the summer and a destination for business travelers or conventions during the winter.

When seasons are related to natural events, they are usually predictable and usually readily observable. For example, the sales of many sporting goods that are dependent on the weather, such as baseballs, gloves, bats and helmets, parallel the season for the associated sport. Although weather is seldom perfectly predictable, we are usually safe when predicting the impact of weather on many industries. Ski resorts, for example, will experience increased winter demand.

These effects extend beyond simple increases in sales for different industries. Seasons are also highly correlated with social phenomena. Aggravated assaults peak in the summer season while heart-attacks decrease in the summer season. The spring season brings peak numbers of triplet births and suicides. Single births, in contrast, usually have a peak season in the late summer. Half of all adolescents first have intercourse from during the months of May, June, July and August. Stroke deaths for males and females are both highly seasonal. The first peaks in the late autumn and the later peaks in the Winter. The peak period for high blood pressure deaths is during December to April, and off-peak period is from June to August. Mania or manic episodes increase in frequency during the warmer months. Men tend to grow beards during the summer and remove them in January. 


\section{Made-made Causes}

Beyond natural changes in weather, there are numerous other causes for seasonality. In some cases, seasons remain annual. For example, the predictable Christmas season brings increased demand for gift-items, warehouses, credit card services, travel-related services and restaurants.

Periodic annual government action, such as taxation, often causes seasonal patterns in demand. Durable goods retailers experience increased demand during periods following tax refunds. Income tax preparation guides and related books hit the best-seller list in periods when firms and consumers need to prepare tax returns.

Government actions can also change seasonal demand. The government, for example, can change the date when a holiday is celebrated or the deadline of filing required documentation. All of these actions can have a profound effect on demand in numerous industries.

In some cases, industries themselves create their own seasonal patterns. Periodic trade-shows foster seasonal activities, such as new product or service releases. New auto releases create autumn demand in auto-related industries. Although it is often difficult for any one firm to change the industry's seasonal pattern, a group of firms might be able to make permanent season shifts.

Most natural seasonal patterns are annual. Other causes of seasonality, however, can create monthly seasonality, weekly seasonality or hourly seasonality. Airlines, amusement parks, beauty salons, restaurants, car rentals, cinemas, communications, construction materials, education, public utilities, employment agencies, financial services, and lodging all experience non-annual seasonal demand, sometimes in addition to seasonal demand. Airlines experience hourly seasonal demand from business travelers in the early mornings and late afternoons. Many amusement parks observe increased demand on week-ends. Beauty salons observe increased demand on Friday and Saturday afternoons. Restaurants experience increased demand at meal-times and on week-ends. Cinemas experience increased demand on nearly all holidays.

\section{IMPACT OF SEASONALITY}

\section{Concentrated Sales}

Many companies faced concentrated periods where most of their sales occurs. Scotts Company, for example, is the country's leading producer and marketer of consumer turf and lawn care products. Scotts faces 70 percent of its sales during the 
March and June quarters. For another example, consider storage batteries in autos. For good reason, batteries are usually replaced in the Winter when they most often failure.

The weather may be the key for many travel-related businesses, such as ski resorts, that depend on either snow or sun-drenched beaches. Cold weather may also increase the demand for chemicals and fuels (e.g., natural as) whose consumption moderates temperatures or controls growing conditions. Finally, weather traditionally impacts agricultural activities and related industries because weather impacts which when crops should be planted and harvested, as well as, crop yield. Tractor Supply Co.'s, for example, experiences peaks in both sales and profits in the second and fourth fiscal quarters. Lighting products are also highly seasonal because the hours and intensity of daylight varies across seasons. For these products, sales peak during the fall and winter months when Daylight Savings Time ends and the days become much shorter. Sales of indoor foliage plants also vary dramatically by season. For these plants, $40 \%$ of sales revenues usually occur in the spring season. In addition, another $30 \%$ of sales revenues occur in the summer season. Also weather related are sales of car care items. These items include waxes, polishes, paint striping, wheel treatments, finish protectors, wiper blades and so on. The sales of these items are highly seasonal. They usually peak in the spring and are quite low in the winter. Possibly because of weather related illnesses, sales of various over-the-counter drugs, such as acetylsalicylic acid, i.e., aspirin, are highly seasonal.

Seasonality becomes so pronounced in some industries that these industries routinely incur losses in the off-season. For example, elementary an secondary textbook businesses often incur operating losses during the off-season, i.e., in the first two fiscal quarters.

\section{THE SHAPE OF THE SEASONAL PATTERN}

Seasonal pattern can take different shapes. Figures 1 and 2 show two shapes that seem particularly appropriate for theoretical analysis. The first shape (Figure 1) is a step function depicting two seasons: a peak-season and an off-peak season. Both the peak season and off-peak seasons have the same intensity throughout. The second shape (Figure 2) shows a smooth transition from peak to off-peak sales with no clearly delineated peak and off-peak season. 
Figure 1

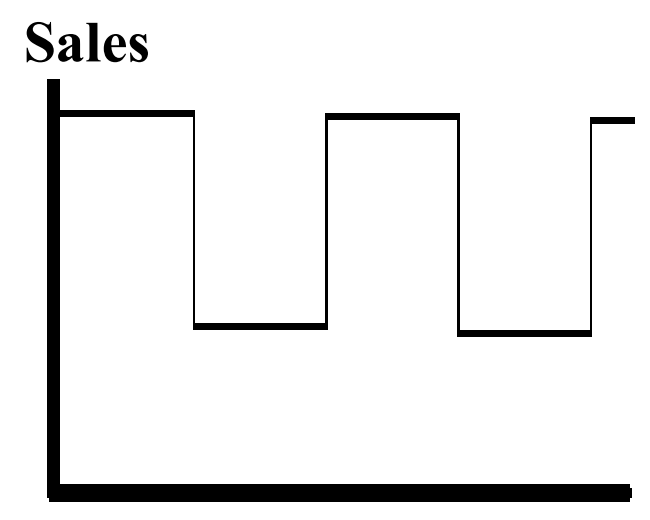

\section{Time}

Figure 2

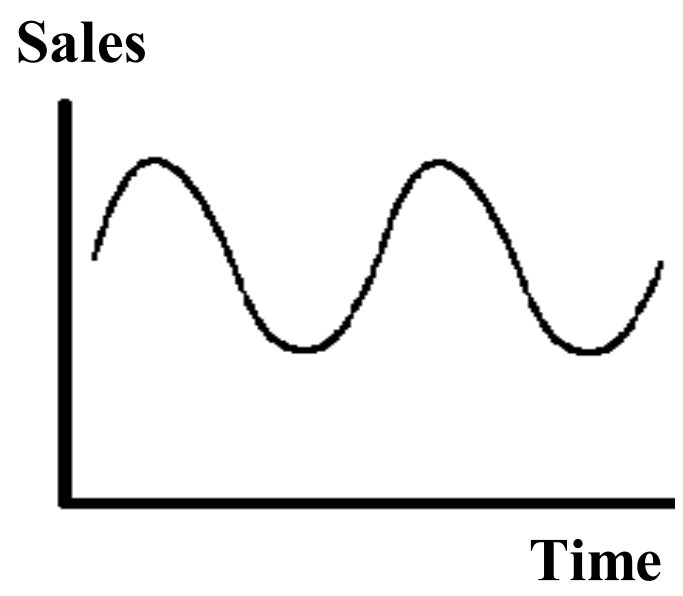

Both of the seasonality patterns (shown in Figures 1 and 2 ) are simple recurring patterns involving only a peak and off-peak season. Both of these simple seasonality patterns are convenient patterns for theoretical work. However, even these patterns provide complex implications.

For example, suppose we are examining the optimal launch of a new durable. When the life-cycle of the durable is extremely short compared to the duration of the peak season, the first sales pattern (Figure 1) usually implies either launching when the durable is complete or waiting to the beginning of the next peak. In the second sales pattern (Figure 2), intermediate launches are more likely. Moreover, as the life-cycle of the durable increases, more complex launching strategies can become profitable. A 
durable with a slow growth followed by high-peak sales may find it desirable to launch immediately before the peak and use word-of-mouth to enhance the peak.

Although figures 1 and 2 both represent interesting seasonality patterns for theoretical work. Real seasonality patterns tend to be far more complex. Figures 3 and 4 provide examples.

Figure 3

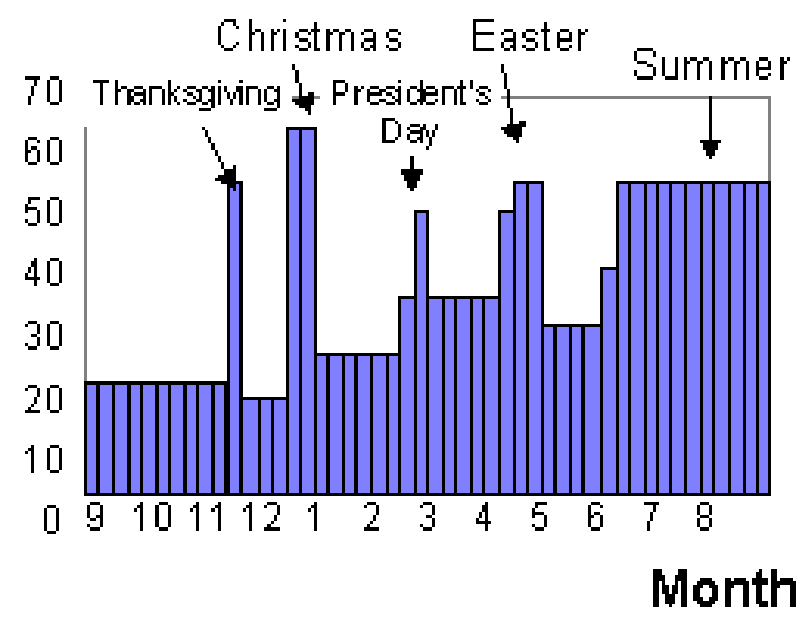

Figure 4

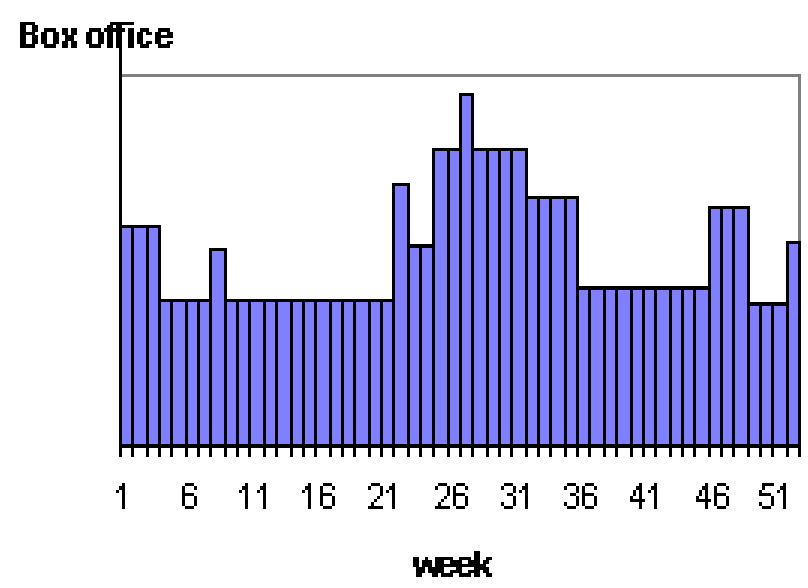

Figure 3 shows the actual seasonality pattern for Disney World in Florida while Figure 4 shows the actual seasonality pattern for the motion picture industry (domestic sales). The recent literature, contains many interesting recent articles on this later industry (e.g., see Sawhney and Eliashberg 1996). 


\section{MODELING SEASONALITY}

\section{Different Views of Seasonality}

\section{A Market Size Interpretation}

One common view of seasonality is that high seasons merely increase the size of the market. Suppose, for example, a market consists of 100 buyers during the peakseason. During the off-peak, demand reduces to half of peak demand, i.e., 100/2. So, we might say here that the off-peak market consists of only 50 buyers.

Although this argument appears reasonable, it does require many additional assumptions before the argument becomes consistent. For example, suppose we launch a new product or service in the peak period and obtain sales of 60 units. Now consider what our sales should be in the off-peak period.

If our product or service is a non-durable, we might expect $60 / 2$ or 30 units of sales in the off-peak period. That expectation is consistent with a zero-growth assumption. In other words, sales would have continued at a level of 60 units were it not for the decreased demand occurring during the off-peak period.

We might say that half of our current buyers are no longer in the market. The buyers who leave are similar in every respect to the buyers who remain. Hence, our sales merely decrease to half of their original levels or $60 / 2$ or 30 units.

Hence, merely changing the market size is consistent with a non-durable product or service with zero growth, assuming that the buyers who leave the market are similar to the buyers who remain. However, now consider a single-purchase durable product or service. Here, once a buyer purchases our service, they leave the market. For example, once the buyer sees a movie at the theater, the buyer does not return to see it again in the second period.

Here, merely changing the market size does create conceptual problems. For example, again suppose that 60 buyers purchase the durable during the peak period when the durable is introduced. In that case, these 60 buyers would leave the market. It seems that the 60 buyers leaving the market should have an impact on sales in the offpeak period. However, our prior assumption is that the market size in the off-peak period is 50 regardless of the number of sales in peak period.

We might think that we should decrease the off-peak period by the number of buyers who left the market, that is, 60 . However, doing that calculation would leave a negative market size, i.e., 50-60, in the second off-peak period. Obviously, we can not simply subtract the number of buyers in the first period to obtain the market size in the second period. 
We must consider more precisely what is happening in the market. We might say that in the off-peak period, the probability of a purchase by a buyer decreases. For example, in the peak period, the probability of seeing the movie is $60 \%$ and $.6 \times 100$ buyers see the movie. In the second off-peak period, the probability of seeing the movie is only $30 \%$ and so the market size remains at 100 buyers but buyer probabilities of purchase decrease. In some markets the probability of purchase may decrease to zero or near zero. In other words, all the buyers remain in the market, but all or many of these buyers have decreases, possibly dramatic, in their purchase probabilities.

When we allow the market size to remain constant, we avoid the conceptual problems associated with both durable services whose sales exhaust their market and non-durables whose growth depends on sales in prior periods. For example, consider the movie case. In the peak period, the purchase probability in the peak period would be $60 \%$ and sales would be $.6 \times 100$ or 60 buyers. In the second period, $100-60$ or 40 buyers would remain in the market. In the second off-peak period, however, the probability of purchase decreases to $30 \%$. With a market of 40 buyers and a purchase probability of $30 \%$, we would expect sales of $3 \times 40$ or 12 purchases.

Hence, adjusting the purchase probability is a more logical approach to modeling seasonality than an adjustment of the market size. By adjusting purchase probabilities, the accounting of the number of buyers who have purchased the service remains uncomplicated by the transitions to different seasons. This argument becomes even more cogent when we introduce marketing mix variables.

Suppose again that we introduce a service in the peak-season. In the peak-season, we might use marketing mix variables such as advertising and promotions that are discontinued in subsequent periods. Here, many buyers may become aware of the service in the first period and those buyers would continue to be aware of the service in subsequent periods regardless of whether the subsequent periods are peak or off-peak periods. For example, advertising might make 90 of 100 potential buyers aware of a new service when that service is introduced in the peak period. Those potential buyers would continue to be aware of the service in all subsequent periods. Entering an off-peak period may diminish sales by decreasing purchase probabilities but awareness would remain at 90 people. Moreover, were we to enter a high-season, the number of aware customers would not increase beyond 90 people merely because purchase probabilities increase. The number aware of the service would remain consistent over time.

\section{Purchase Rate Interpretation}

Radas and Shugan (1998b) consider another interpretation of seasonality. They consider seasonality to be a change in the rate of purchases or transformed time. In other words, the rate of purchasing increases during the high season and decreases 
during low seasons. The rate of purchase, for example, may vary from week to week following a weekly seasonal pattern.

Note that the rate of purchase similar to the concept of a purchase probability, however, it is a more general concept. The rate of purchase can be applied to both models with and without fixed market sizes. Moreover, when the service is a non-durable exhibiting no growth in sales, the rate of purchasing concept reduces to the market size interpretation of seasonality.

When the Radas and Shugan (1998b) approach, we interpret seasonal changes as changes in the rate at which time progresses. We can understand this interpretation as follows.

A service may have a life-cycle that would exist without seasonality. This life-cycle is a time series of sales. When we lower price we might change some parameters in that life-cycle. When we advertise we might change other parameters. However, the lifecycle would describe the sales of the service, in the absence of seasonality.

When seasonal effects occur, the rate of growth along the life-cycle changes. As the season becomes stronger, the growth increases. One month in the peak season may be equivalent to two months in the off-peak season. One month of sales in the peak season may generate two months of off-peak sales. One month of advertising in the peak-season may produce the impact of two months of off-peak advertising. In other words, entering a peak season increases the rate at which time progresses.

As the season becomes weaker, the growth along the life-cycle decreases. One month in the off-peak season may be equivalent to only a few days in the peak season. One month of sales in the off-peak season may be equivalent to only a few days of sales in the peak season. One month of advertising in the off-peak season may produce the impact of only a few days of advertising in the peak season. In other words, entering offpeak periods decreases the rate at which time progresses.

\section{Other Interpretations}

We have and continue to focus on the modeling of seasonality and the incorporation of seasonality into decision models. It is, however, possible to take another interpretation of seasonality. It is possible to consider seasonality to be a contaminant in the data that merely prevents a clean estimation of the model of interest.

This interpretation of seasonality suggest that seasonal influences should be removed from the data before analyzing that data. For example, we might divide our currently monthly sales by the sales in the same month during some past base year. By dividing the sales of each month, in the current year, by the sales in the respective month during the base year, we can examine growth and the impact of management decision variables without observing clear seasonal effects in the so-called deseasonalized data. 
There are many possible methods for deseasonalizing data beyond the method of dividing by some base number. For all of these methods, however, we do not avoid the problem of understanding seasonality. When we employ any of these methods, we make an implicit assumption about the way we expect seasonality to impact our data. Moreover, we assume that seasonality has little or no impact on the variables of interest in our model other than sales. This assumption may or may not be consistent with the underlying model.

Consider a simple example. Suppose our underlying model is that everyone who is exposed to an advertisement in one period, buys in the next period. So if an ad reaches 100 people in April, our unit sales in May are 100 people. Now suppose that we place 100 ads in April, we would expect unit sales of 100 in May. However, these 100 unit sales would be predicted based on deseasonalized data, i.e., sales data where the impact of seasonality has been removed. The actual sales prediction, therefore, would need to be adjusted for seasonality. If May produces twice the demand of April, we would need to double our forecast of 100 and predict unit sales of 200 units in May. Although using this seasonal adjustment may be consistent with the view of seasonality as a contaminant, it seems inconsistent with the underlying model of how advertising works. Here, 100 people buy the product who did not see the ad in April. Adjusting for seasonality implicitly changes the theory of the underlying model because the model only sees the deseasonalized data and all estimates, therefore, are only based on the deseasonalized data. In this example, removing seasonality makes a strong assumption. It assumes that high seasons produce new buyers who have the same awareness and knowledge as the old buyers from last period.

\section{A Time Transformation Model of Seasonality}

It is beyond the scope of this chapter to present the mathematical details of the seasonality adjustment presented by Radas and Shugan (1998b). Instead, we present a more intuitive interpretation.

Consider a service with a life cycle function. The life cycle function represents sales at each future time. The function may or may not be dependent on marketing mix variables. The service will follow this life cycle in the absence of seasonality.

Radas and Shugan (1998b) suggest that as the season intensifies, i.e., we enter a high season, the service ages more quickly along its life cycle. Conversely, when we enter a low season, the service ages less quickly along its life cycle. Hence, seasonality merely alters the aging process and can be simply modeled as a transformation of time.

This interpretation of seasonality has the advantage of not altering the assumptions underlying the original life cycle. In other words, if we hypothesize a life cycle with some well-developed theory of diffusion, marketing-mix affects, lagged advertising effects and 
so on, seasonality has no impact on either our theory or the predicted life cycle. However, the time transformation allows us to transform our life cycle from what our theory predicts to what we should observe when seasonality is present.

In this chapter, we adopt that theory of seasonality and some of the subsequent sections discuss the implications of that theory. However, we should note that for mature services, whose sales no longer exhibit a systematic trend, the transformation of time interpretation provides the same predictions as the changing market size interpretation of seasonality. In other words, both interpretations of seasonality are indistinguishable when sales are not trending upwards or downwards.

\section{RECENT FINDINGS ON SEASONALITY}

\section{Launching New Services}

\section{The Launching Problem}

Radas and Shugan (1998b) study the introduction of new durable services and services, such as motion pictures. A buyer purchases a durable only once. Hence, durable goods sales start at some positive level and eventually decline to zero. In some cases, however, sales decline to a maintenance level consisting of new buyers entering the market and replacement purchases. This maintenance level of sales, generally, is much smaller than sales during the growth phase of the new service.

A firm can launch a new durable as soon as the durable is developed, regardless of whether development is completed during a high or low season. The firm can, alternatively, wait to launch the durable until the next high season. There are several advantages to waiting until the high season.

The high season may bring increased opportunities for distribution. It may be very difficult to obtain distribution for a new service during the off-peak season. A retailer, for example, may be unwilling to carry new winter garments at the end of the winter season. With a decrease in selling effort for the category, it may be very difficult to obtain distribution for a durable in the off-peak season. Increased distribution suggests more rapid growth along the life cycle.

The opposite situation, however, occurs for some single-purchase services and services including some motion pictures. In the motion picture industry, theaters or exhibitors sometimes have only limited ability to increase and decrease allocations during different seasons. They may schedule later shows and eliminate discounts during peak periods, but exhibitors of motion pictures may still have an insufficient number of films during the off-peak season. In this case, launching during the off-peak season may 
provide more distribution for new films with, of course, far fewer people going to the theater each week (Krider and Weinberg 1992).

Another factor is the time value of money. After investing in a new service, the service provider would like to get a return on that investment as soon as possible.

Radas and Shugan (1998b) show that the shape of the new service's sales along its life-cycle is very important in determining when to launch of a new service. For example, they consider two typical shapes for the sales, the exponential life-cycle (shown in Figure 5 and discussed by and the Bass diffusion life-cycle (shown in Figure 6). These are the sales curve which would exist in the absence of seasonal changes in demand.

Figure 5

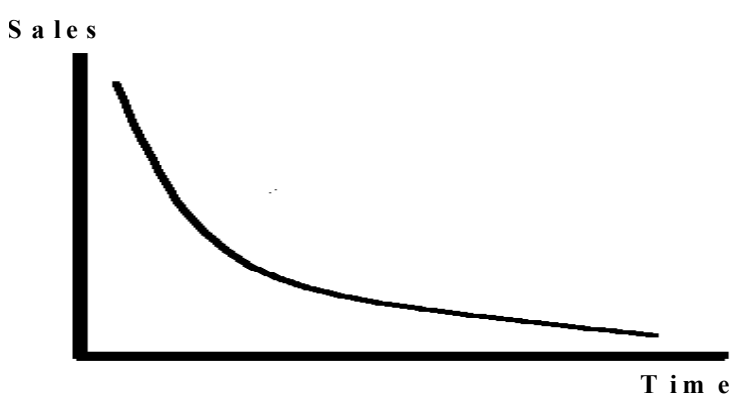

Figure 6

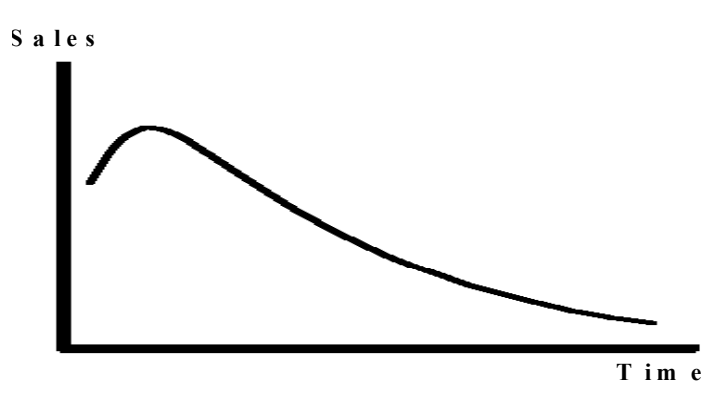

The exponential life-cycle corresponds to a durable whose sales slowly exhaust the market. The diffusion life-cycle corresponds to a durable whose initial awareness may be low. However, as initial sales occur, word-of-mouth among prior buyers causes an acceleration in sales. Eventually, as the number of buyers increases, the market becomes saturated and sales peak. As more buyers purchase the durable, the market becomes exhausted and sales decline to zero.

\section{The Service's Life}

Suppose that we complete the development of a new product or service during the off-season. We want to know whether we should launch that service now or wait to launch it in the peak-season or the next high season. If we launch now, the life-cycle of 
the service will follow an exponential curve. If we wait until the high season, the life-cycle will again follow an exponential curve but the curve will start at a much greater level and we will achieve greater sales.

Radas and Shugan (1998b) study this situation. They examine two cases. In the first case, the life time of the product or service is endogenous. Here, the life of the service is determined by the seller or, in the case of motion pictures, the exhibitor. The seller continues to carry the service until the potential discounted sales fall below some critical level. When the seller expects the service's potential sales to be sufficiently small, the seller drops the service. Hence, the life of the service depends on its sales which, in turn, depends on when the service is launched.

The other case involves a service with an exogenous life. Here, the service provider (or in the case of motion pictures, the studio), signs a contract with the distributor (or exhibitor) to carry the service for a fixed length of time. Here, the service's life is exogenous or pre-determined before the launch.

\section{Launching Strategies}

Radas and Shugan (1998b) find that when the life of the service is endogenously determined, we should launch the service whenever it is completed. In other words, we should never wait until the high season. The intuition underlying this result suggest that the service enjoys a longer life during the off-peak season because it takes a longer time to exhaust the service's life.

Hence, when a service's life-cycle exhibits an exponential pattern and the service is discontinued when its sales potential drops below a particular level, the service should be launched when it is completed. The benefits of launching now exceed the benefits of waiting for higher seasonal demand because, when the life is endogenous, the service enjoys a longer life during the off-peak season. The discounted sales during the season quickly drop below the cut-off, so the life is short and the advantage to waiting is small.

Now let us consider the case when the service's life-cycle is exogenous or predetermined by contract. Here, there are two cases. In the first case, the service's lifecycle is short compared to the length of time between now and when the high season begins. The second, case the service's life-cycle is long compared to the length of time between now and when the high season begins.

Consider the case when the service's life-cycle is both exogenous and short compared to the duration of the season. Possible strategies are shown in Figure 7. 


\section{Figure 7}

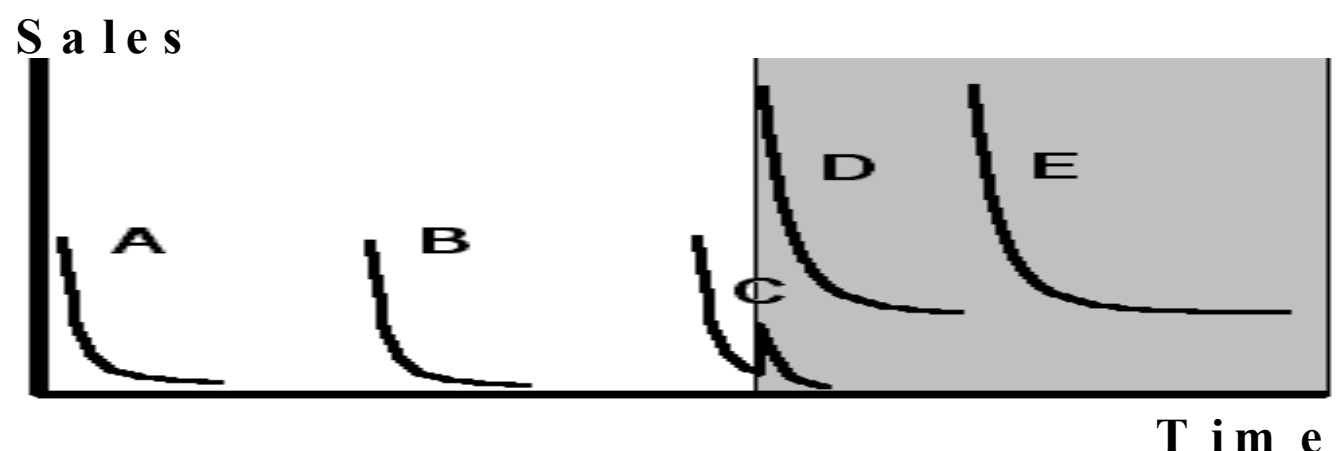

The shaded area in Figure 7 represents the high season. Here, we can launch now, in which case the entire life-cycle occurs in the low season (see curve A). We can wait a short time, in which case, again the life-cycle in entirely in the high season (see curve B). We can wait until some of the tail of the life-cycle is in the high season (see curve $C$ ). We can wait to exactly the beginning of the high season (see curve D). Finally, we can wait until the after the beginning of the high season (see curve E).

Here, the service faces the same life during the peak and off-peak season, but far less sales off-season. The launching decision must consider compromising some sales now against greater sales later. For short-lived services, it does not pay to wait if no part of the sales curve enters into peak season. So if waiting is at all profitable, the delay will have to be long enough to bring part of the sales tail into the season. This will accelerate the sales and thus increase revenues. Hence, profits are lower for curve $B$ than curve $A$. In fact, profits decline as curve B moves to the right.

It is possible to show that curve $E$ provides less profits than curve $D$. If the peak season is flat, the best delay is exactly to the beginning of the season. Any longer waits will not bring additional increase in sales, but will certainly increase losses from discounting. These constraints leave either curve $A, C$ or $D$ as possible introduction strategies.

Note that the service faces the same life when launching now (curve A), waiting until the tail reaches the high season (curve $\mathrm{C}$ ) or launching at the beginning of the high season (curve D). However, the service enjoys the lowest sales in the first strategy (curve A) and the highest sales in the last strategy (curve D), respectively.

\section{When to Wait}

Waiting to the high season (curve $\mathrm{D}$ ) becomes more profitable, relative to other strategies, when the difference in demand between the high and low season increases -larger differences will bring sharper increases in sales. Waiting to the high season (curve 
D) also becomes more profitable when the time to the high season decreases -- longer waits bring loses incurred from discounting. Waiting to the high season (curve $D$ ) becomes more profitable when demand in the low season decreases because there is less of an opportunity cost. Finally, the advantage of waiting depends positively on increase in sales that the peak season brings, and negatively on the discount rate.

If service's life is sufficiently long, the service will pass through the peak season still early in its life. Therefore, the benefit of waiting will be smaller than the impact of discounting. If the peak season is far away, the loss incurred by discounting will outweigh the increase in sales brought by waiting until the peak season.

Figure 8

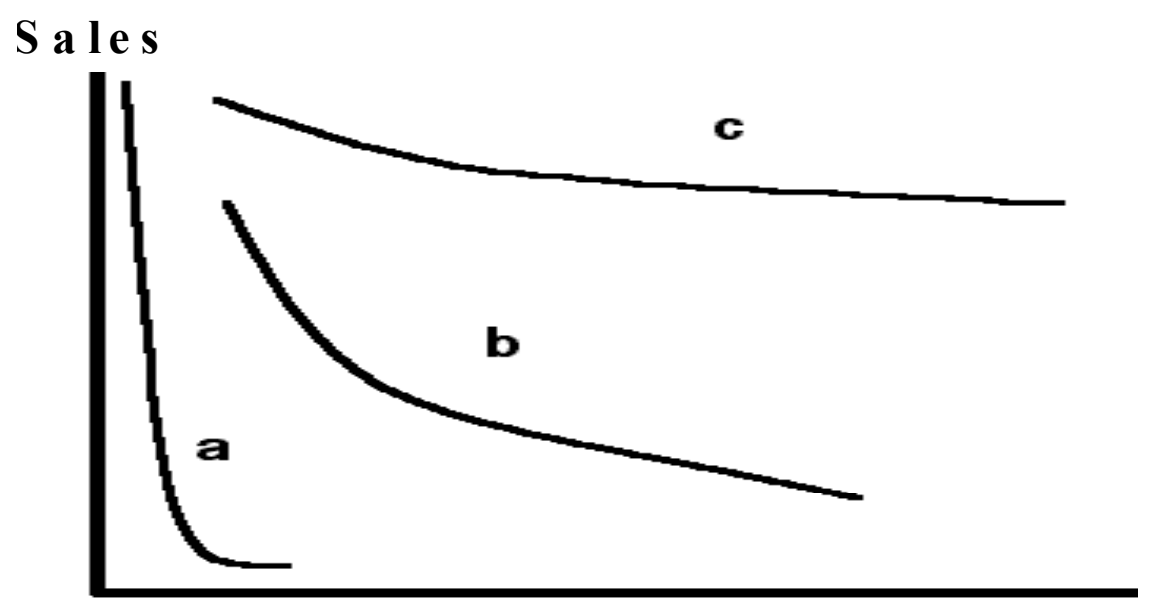

T im e

The curvature of the life-cycle is also very important (see figure 8). Waiting to the high season becomes more profitable, relative to other strategies, when the curvature is intermediate (curve $\mathbf{b}$ in Figure 8). Launching now becomes more profitable when the curvature is very large (curve a in Figure 8) or very small. (curve $\mathbf{c}$ in Figure 8)

This result suggests that when most of the service's sales are early in its life, our launch should be immediate. When most of the service's sales are late in its life, we should also launch now. However, intermediate cases favor waiting for the peak season.

Note that, the high season tends to accelerate sales and move these sales forward. When the curvature is very large, there is less advantage to that acceleration because sales are already accelerated in the low season. When the curvature is very small, there is also less advantage to that acceleration because the impact of the acceleration is very small. With intermediate curvature, however, the acceleration can be meaningful and waiting to the high season can increase profits.

Finally, as we have already stated, there are three possible launching strategies. We could launch now (Figure 7- curve A), wait until the beginning of the high season 
(Figure 7- curve B) or use some intermediate wait (Figure 7- curve C). It is can be shown that with an exponential life-cycle (shown in Figure 5), the intermediate wait is possible but very rare. Very specific and complex mathematical conditions must be met before the intermediate wait strategy becomes the most profitable.

This is not the case with the Bass diffusion life-cycle (shown in Figure 6). Here, intermediate waits are more likely to provide greater profits than with the exponential function. Intermediate waits can provide greater profits than immediate launches or waiting to the beginning of the next high season. With the diffusion life-cycle, there is a period of growth before sales peak and subsequently decline. It is possible, that we should delay the introduction so that all or most of the growth period occurs in the low season while the peak and subsequent decline in sales occurs in the high season. Hence, an intermediate wait (Figure 7- curve $\mathrm{C}$ ) is more often a better launching strategy when the sales of the service follow a Bass diffusion life-cycle (Figure 6).

These intermediate waits can be optimal because diffusion models exhibit an initial period of growth. It is sometimes best to have that growth occur in the low season. Here, the service provider should launch shortly before the high season and start the diffusion process so that peak sales occur in the peak-season.

The intuition for this result lies in the shape of the curve. As we move into the future, incremental seasonal sales increase with the exponential model but decrease in the growth phase of the diffusion model. With an exponential model, therefore, the benefit to waiting continues to increase until all sales occur in the high season.

Consequently, the optimal solution is to push all sales into the high season or launch immediately.

With a diffusion model, after the peak enters the high season, the incremental benefit to waiting decreases. Although extreme solutions are still common, it is possible that the benefit to waiting exceeds the cost before the entire curve is in the high season.

The Bass diffusion model has parameters representing the rate of diffusion through the population. The findings on these parameters are similar to those for the exponential distribution. When the parameters are very large or very small, the relative profits to launching immediately increase. When the parameters take moderate values, a waiting strategy is sometimes more profitable than launching immediately. See Figure 9. 
Figure 9

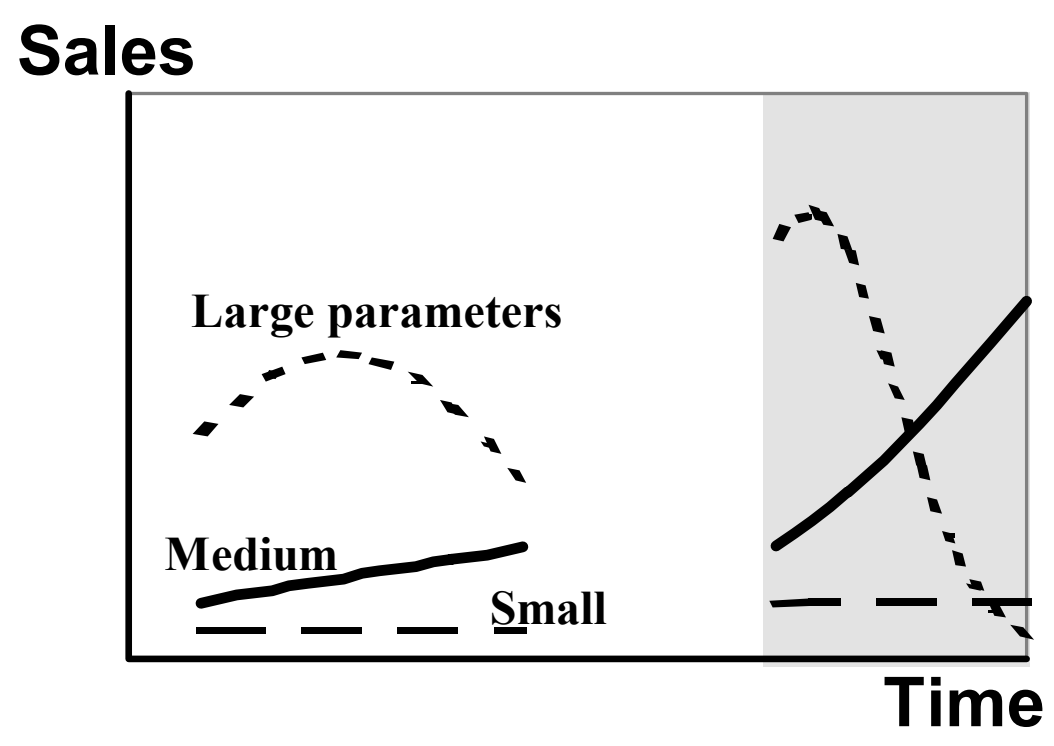

Very small parameters (the dashed line in figure 9) yield a very slow growth whenever we launch. Although waiting provides somewhat higher sales, the discount rate favors launching now. Here, the time value of money overwhelms the incremental sales possible during the high season.

With very large parameters (the dotted line in figure 9), growth is so rapid, that the service completes much of its life in the low season. Waiting provides some incremental sales at the end of the life-cycle. These sales are relatively small. Here, the time value of money dominates.

With intermediate (the solid line in figure 9), the service is unable to complete the rapid stage of its life-cycle during the low season. Waiting so that some sales are in the high season, allows accelerated growth, and the service completes this rapid stage. Here, waiting for the high season dominates. The incremental high-season sales compensate for the time value of money.

\section{Shifting Demand}

\section{The Concept of Shifting}

Many service providers employ a strategy called "Demand Shifting". This popular strategy tries to shift demand from high seasons, when demand sometimes exceeds capacity, to low seasons when most service providers are operating well below capacity constraints. There are many examples of demand shifting. One example involves city 
governments trying to shift automobile traffic from rush hour periods to less crowed times of the day. Some cities have attempted to shift demand by encouraging the staggering of employee work hours. For another example of a demand-shifting strategy consider electrical utilities who give their customers timing devices so that customers can start electrical appliances such as dishwashers during off-peak periods when the customers may not be at home. Still another example of this strategy involves water authorities who restrict lawn watering times to times when demand for water is low. Finally, the postal system's "Mail Early for Christmas" campaign is a classic example (Shostack 1977).

\section{The Profitability of Shifting}

At first glance, shifting demand appears to be a reasonable strategy. As a service provider, we may have a seasonal time period when we are operating at capacity and we are unable to service additional customers. It seems reasonable to try to shift some of those customers to an off-peak period when we have sufficient capacity to serve them.

Despite the apparent desirability of this strategy, the strategy is wrong (Radas and Shugan 1998a). Although not-for-profit services may find demand shifting strategies are an effective way of achieving social objectives, shifting strategies offer no more profits and, often, decrease overall profits.

Demand shifting strategies become unprofitable because their costs exceed their benefits. To generate sufficiently high demand during the peak season to allow shifting, we must price at a sufficiently low price. Associated with that low price is an opportunity cost. We charge all customers, who receive the peak season service, a slightly lower price than each of them would be willing to pay. The additional profits generated during the off-season, at a much lower price, are insufficient to overcome the opportunity cost of charging that lower price during the peak season. In fact, the best strategy, as we will see, is to enhance peak demand.

\section{Bundling as a Strategy}

Now, let us consider a bundling strategy that enhances peak demand. This strategy offers customers, who purchase our service during the peak period, free service during the off-peak period. Here, those customers who purchase during the peak-period at peak prices also obtain off-peak service for no additional cost. Examples of this type of bundling includes Frequent Flier clubs and cellular telephone companies (for example Ameritech Cellular Services offers to new customers free service in off-peak periods, which is from 8 PM to 6 AM on weekdays and all day long on weekends). In other cases, customers buy a package consisting of peak and off-peak units of the service. 
Figure 10

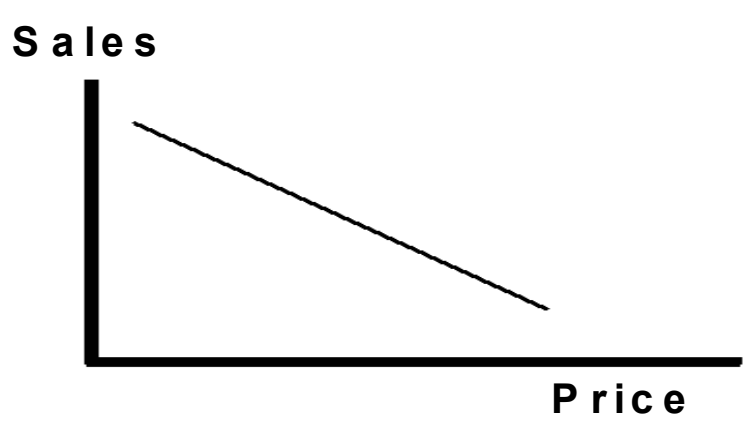

Figure 11

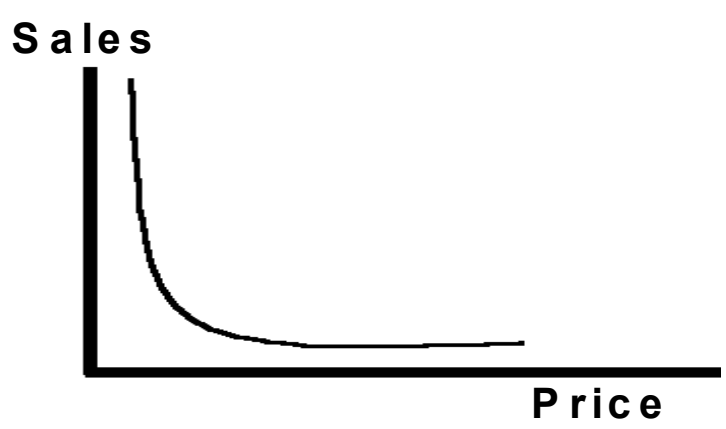

Being more precise, requires some knowledge about the demand function. For our discussion, let us consider two possible demand functions. The first is the linear demand function whose shape is shown in figure 10, and the second demand function is the constant elasticity demand function whose shape is shown in figure 11. Note that the shapes may vary according to the demand function's parameters. However, the following conclusions are valid regardless of the specific shapes.

It is possible to show that when the demand is linear or constant elasticity, it is never more profitable to shift demand from the peak season to the off-peak season. As a profit-seeking service provider, demand-shifting from the high to the low season is never our best strategy. Suppose that, given peak-demand, we set our price to maximize our profits and we find that, at that best price, demand exceeds our capacity. Rather than trying to shift the excess demand to the off-peak period, we should, instead, increase our price during the peak season. We should increase our price until the number of customers, that we expect to demand our service during the peak period, exactly equals our total available capacity. By setting our peak-season price to that level, we discourage customers who seek the service during the peak period and, essentially, eliminate expected excess peak-season demand. That leaves no demand to shift to the off-peak period. 


\section{The Profitability of Bundling}

Unlike shifting strategies, bundling can provide greater profits. In effect, bundling works in the reverse direction. Bundling increases peak demand by enhancing the value of buying the service during the peak-period. In other words, a bundling strategy is a reverse-shifting strategy, shifting demand to the peak-period.

Bundling can be profitable because the service provider makes considerable profits from raising the price during the peak-period. During the period of peak demand, the service provider is operating at capacity. During that period, small price changes can have a dramatic impact on profits.

When (1) we face a linear demand function; (2) the off-peak market potential is less than twice available capacity, and (3) bundling expands peak-season market potential, then some bundling improves profits. Hence, under very reasonable conditions, some bundling improves profits. When the off-season market potential is sufficiently small, then there will be some excess off-peak capacity. This situation occurs whenever the off-peak market potential is less than twice the available off-peak capacity. When we have that excess capacity, it is always beneficial to profits to use that excess capacity during the peak-season to enhance peak-season demand. When we are at capacity during the peak-period, bundling allows us to charge a higher price for every unit of that capacity. When we are not at capacity during the peak-period, bundling allows us to increase sales during the peak season and, perhaps, increase sales to capacity.

Now consider the case when: (1) our peak-season market potential is less than our available capacity, (2) our peak price sensitivity is sufficiently large, and (3) there is a large proportion of customers who have bought the bundle, who would not have bought otherwise. When these three conditions are present, it is most profitable to bundle all sales. With a very large capacity, our off-peak service should not be sold separately. We should always bundle it with the peak-season service. One example of this is Ameritech's cellular phone rates, where a customer buys peak time together with offpeak time, and the customer never has the opportunity to buy off-peak time alone.

Again, consider the situation when our demand is linear in price. We define adjusted market potential as the demand which would result from pricing at cost. When our adjusted peak-season market potential is greater than twice our capacity, then our best strategy depends on our off-peak season market potential. When our adjusted offpeak season market potential is much larger than twice our capacity, we should not bundle any of our peak-season sales. When our adjusted off-peak season market potential is somewhat larger or smaller than twice our capacity, we should bundle some, but not all, of our peak-season sales. When our adjusted off-peak season market potential is very small, we should bundle all of our peak-season sales. 
Here we explore the profitability of bundling when our adjusted peak-season market potential is large relative to our capacity (greater than twice our capacity). With only one exception, this statement suggests that the advantage of bundling increases as the adjusted off-peak season market potential becomes smaller. The intuition behind this result is straightforward. When the adjusted off-season market potential diminishes, the value of capacity during the off-peak season also diminishes. With less adjusted off-peak season market potential, maximizing off-peak season profits requires less capacity.

As each unit of off-peak capacity becomes less valuable, the advantage of bundling increases because our cost of bundling is precisely the opportunity cost associated with off-peak capacity. Our cost of bundling is minimized when off-peak capacity has no value to us.

Given that intuition, we might wonder why we have one exception when our adjusted off-season market potential is just less than twice our available capacity. In that situation, we still find bundling profitable, but bundling only part of our sales is more profitable than bundling all of our sales. This result has as much to do with price sensitivities as it does with off-peak capacity.

The difference between price sensitivities for the peak-season and off-peak season can be an important factor influencing the profitability of bundling. The larger this difference in price sensitivities, the more profitable bundling becomes and the optimal number of bundled sales increases. Consequently, service providers with little capacity should avoid bundling when peak-season and off-peak price sensitivities are similar. They should use bundling when prices sensitivities are very different. When the difference in sensitivities is very large, it becomes optimal to bundle the entire off-peak capacity.

We can conclude that bundling becomes more profitable as the adjusted off-peak season market potential diminishes, except when off-peak sales are close to capacity and our off-peak price sensitivity is small relative to peak-season price sensitivity. When off-peak price sensitivity is low, we are able to charge more for off-peak season capacity by having a higher off-peak price. Charging more for off-peak capacity makes that capacity more valuable because each unit of that capacity now generates more revenue. Bundling may force us, when we are near capacity, to forgo some of that revenue. Hence, we might want to limit the quantity of bundled sales when the off-peak price is high and we are operating at near capacity during the off-peak season. Table 1 summarizes these findings: 
Table 1: Summary of Bundling Results

\begin{tabular}{l|lc}
\hline & Large peak demand. & Small peak demand. \\
\hline Bundle all sales when: & Small off-peak demand. & Large differences between \\
& & peak and off-peak \\
& & price sensitivity. \\
& & Many customers buy bundle \\
& who would not have \\
Bundle some sales when: & Intermediate off-peak & otherwise bought. \\
& demand. & Small off-peak demand. \\
& Bundling expands peak- & season demand. \\
Do not bundle when: & Very large off-peak demand. & \\
\hline
\end{tabular}

Finally, we consider the case of the constant-elasticity demand function. Consider the case when the peak market potential is larger than capacity. In that case, when the off-peak market potential is sufficiently small relative to capacity, bundling improves profits. When the off-peak market potential is large relative to capacity, then bundling can still improve profits when peak-season market potential is sufficiently large.

When the off-season market potential is sufficiently small, then there will be some excess off-peak capacity. This excess capacity can be used during the peak-season to enhance peak-season demand. When we are at capacity during the peak-period, bundling allows us to charge a higher price for every unit of that capacity. When we are not at capacity during the peak-period, bundling allows us to increase sales during the peak season and, perhaps, increase sales to capacity. 


\section{CONCLUSIONS}

Almost every service displays some seasonality. We discussed one approach that provides a theoretical foundation for modeling seasonality. That approach transforms time so that during high seasons, time moves more quickly than observed time. During the low seasons, transformed time is moving more slowly than observed time.

The transformed-time approaches does more than just adjust sales for seasonal demand. The approach accelerates and decelerates the service's sales and aging along its life cycle. The transformation also provides a way of parsimoniously adding a known seasonal pattern to any dynamic model, without changing the foundation of the original underlying model.

The transformation approach also provides implications for the timing of new service introductions including whether to launch in a current low season or wait for the next high season.

The shape of the life cycle is important. For example, when the sales of the service are continuously decreasing, we should either launch now or wait until the beginning of the next high season. Intermediate waits are less profitable than launching immediately. When early growth rate is either very rapid or very slow in the off-season, we should launch immediately -- waiting to the season fails to improve profits. When growth is intermediate, we can possibly improve profits by waiting to the next high season.

We also conclude that demand shifting strategies are ineffective for private service providers who seek to improve profits. It is better for these private service providers to eliminate excess demand during peak periods, for example with higher peak prices, than to attempt to shift some of this peak demand to the off-peak period. For-profit service providers should, instead, focus on demand stimulating strategies. We show, for example, that we can improve profits through bundling, that is, selling services, during the peak, bundled with free off-peak service. In doing so, we find that service providers should focus on stimulating demand during the peak period, rather than shifting peak demand to the off-peak period. 


\section{REFERENCES}

Krider, Robert E. and Charles B. Weinberg (1998), "Competitive Dynamics and the Introduction of New Products: The Motion Picture Timing Game," Journal of Marketing Research, 35 (February), 1-15.

Lovelock, Christopher (1984), "Strategies for Managing Capacity-Constrained Service Organizations," Service Industries Journal, (November), 12-30.

Radas, Sonja and Steven M. Shugan, (1998a), "Managing Service Demand: Shifting and Bundling," Journal of Services Research, Vol. 1, No. 1, (August), 47-64.

Radas, Sonja and Steven M. Shugan, (1998b), "Seasonal Marketing and Timing New Product Introductions," Journal of Marketing Research, Vol. 35, No. 3, (August), 296-315.

Sawhney, Mohanbir S. and Jehoshua Eliashberg (1996), "A Parsimonious Model for Forecasting Gross Box office Revenues of Motion Pictures," Marketing Science, Vol. 15, No. 2, pp. 113-131.

Shostack, G. Lynn (1977), "Breaking Free From Product Marketing," Journal of Marketing, 41 (April), 73-80. 